\title{
HYPOGLYCEMIA IN NEWBORNS WITH RISK FACTORS OF HYPOGLYCEMIA.
}

1. FCPS (Pediatric Medicine) Consultant Pediatrician THQ Hospital, Rojhan.

2. PGR FCPS (Pediatric Medicine) Postgraduate Resident Department of Pediatric Medicine The Children's Hospital and The Institute of Child Health, Multan.

3. PGR MD, Pediatric Medicine

Pediatric Medicine Unit-2 Mayo Hospital, Lahore.

Correspondence Address: Dr. Fazal ur Rehman

Postgraduate Resident

Department of Pediatric Medicine

The Children's Hospital and

The Institute of Child Health, Multan. fazal171@gmail.com

Article received on: 01/03/2019

Accepted for publication: $10 / 06 / 2019$

\begin{abstract}
Muhammad Ejaz Mazari', Fazal ur Rehman², Muhammad Ashfaq Zafar ${ }^{3}$
\end{abstract}
ABSTRACT... Objectives: Hypoglycemia is a matter of great concern especially in newborns. Its prevalence varies globally as different protocols and feeding policies exist. We aimed this study to find out the incidence of hypoglycemia in newborns with risk factors of hypoglycemia. Study Design: Observational study Setting: Pediatric Medicine Unit-2, Mayo Hospital, Lahore. Period: From $1^{\text {st }}$ January 2018 to $31^{\text {st }}$ December 2018. Material \& Methods: A total of 342 babies born with risk factors for hypoglycemia fulfilling the inclusion and exclusion criteria were considered for this study. Screening for hypoglycemia was performed prior to feeding at 2, 6, 12, 24 and 48 hours of life. Results: Out of a total of 342 newborns with risk factors, 109 (31.9\%) were found to have hypoglycemia. Amongst these newborns, $99(28.9 \%)$ and $10(2.9 \%)$ newborns had asymptomatic and symptomatic hypoglycemia respectively. Among these 109 newborns, majority were male $56(51.4 \%), 70(64.2 \%)$ with gestational age more than 37 weeks, $66(60.6 \%)$ with birth weight more than 2500 grams and $62(56.9 \%)$ small for gestational age (SGA). Amongst newborns who developed at least 1 hypoglycemia episode, 52 (47.7\%) were at 2 hours of life, $31(28.4 \%)$ at 6 hours whereas no hypoglycemia episode recorded beyond 24 hours of life. Conclusions: Screening for hypoglycemia should always be performed in babies who had risk factors of hypoglycemia especially within 24 hours of life. As per our study blood glucose screening should be mandatory in all newborns who are SGA.

Key words: Hypoglycemia, Incidence, Newborns, Risk Factors.

Article Citation: Mazari ME, Fazal ul Rehman, Zafar MA. Hypoglycemia in Newborns with risk factors of hypoglycemia. Professional Med J 2020; 27(1):84-88.

DOI: 10.29309/TPMJ/2020.27.1.3333

\section{INTRODUCTION}

Low levels of blood glucose depict hypoglycemia that can adversely hamper neurological and developmental outcomes in newborns. ${ }^{1}$ Defining hypoglycemia has been a debatable issue in the last few decades especially because it is mostly asymptomatic as brain of the newborn is not fully matured.

In 2011, American Academy of Pediatrics (AAP) stated that it is impossible to label values of glucose for hypoglycemia and AAP defined safe glucose concentrations in their recommendations related to newborns who were at risk of hypoglycemia., ${ }^{2,3}$ Hypoglycemia was defined as blood glucose value less than or equal to $40 \mathrm{mg} / \mathrm{dL}$ by AAP and subsequent breastfeeding and an intervention as per requirement was recommended.

As far as risk factors related to hypoglycemia in newborns are concerned, large for gestational age, small for gestational age, low birth weight, preterms and maternal history of diabetes or hypertension are known ones. ${ }^{4,5}$

Studies calculating incidence of hypoglycemia from around the world have variation in results. This may be due different methods of screening for hypoglycemia as well as difference in practices related to feeding. In a country like Pakistan with limited healthcare facilities and lack of awareness amongst general population, early breastfeeding and warm chain maintenance is not always possible. Blood glucose screening for all newborn in all newborns has its own hazards. It is very important to detect the burden of hypoglycemia in newborns in our setting specially those who have risk factors so this study this study to find out the incidence of hypoglycemia in newborns with risk factors. 


\section{MATERIAL AND METHODS}

This was an observational study done at Pediatric Medicine Unit-2, Mayo Hospital, Lahore from $1^{\text {st }}$ January 2018 to $31^{\text {st }}$ December 2018. Permission from Institutional Ethical Committee was taken before the start of this study. A total of 342 newborns having hypoglycemia risk factors were enrolled. Healthy newborns but those whose mothers were diabetic or had hypertension, birth weight $>90^{\text {th }}$ percentile (LGA), birth weight $<$ $10^{\text {th }}$ percentile (SGA), low birth weight (1800 to 2500 grams) and preterm babies (35-37 weeks) were included in this study. All newborns who were having formula feed or pre-lacteal feed, congenital malformations or those who were admitted in neonatology intensive care unit (NICU) for any reason were not included in this study.

Parents or guardians of newborns were explained about hypoglycemia and its risk to newborns and consent for this study as well as blood testing spanning regular intervals were acquired. Under aseptic precautions, heel prick was done and capillary blood glucose was tested using AccuChek Glucometer (Roche) at 2, 6, 12, 24 and 48 hours of life, prior to feeds. If capillary glucose levels turned out to be $<25 \mathrm{mg} / \mathrm{dl}$, a blood sample was obtained and sent to institution laboratory for confirmatory blood glucose level.

Descriptive statistical analysis was done and measurements were shown in number and percentages using SPSS Version 20.0. Chi square test was applied to see the impact of studied variables on hypoglycemia and $p$ value $\leq 0.05$ was taken as statistically significant.

\section{RESULTS}

Out of a total of 342 newborns with risk factors, 109 (31.9\%) were found to have hypoglycemia. Amongst these newborns, 99 (28.9\%) and $10(2.9 \%)$ newborns had asymptomatic and symptomatic hypoglycemia respectively. Among these 109 newborns, majority were male 56 $(51.4 \%), 70(64.2 \%)$ with gestational age more than 37 weeks, $66(60.6 \%)$ with birth weight more than 2500 grams, $62(56.9 \%)$ small for gestational age, $59(54.1 \%)$ maternal age less than 30 years,
55 (50.5\%) with maternal BMl over 30, 76 (69.7\%) parity status of mothers as multigravida and 70 $(64.2 \%)$ as LSCS mode of delivery. As per history of maternal morbidity, $32(29.4 \%)$ had history of diabetes mellitus while 48 (44.0\%) hypertensive.

When newborns were compared for the all the studied risk factors, small for gestational age newborns were seen significantly (0.025) more having hypoglycemia while others turned out to be statistically insignificant $(P>0.05)$.

Amongst newborns who developed at least 1 hypoglycemia episode, $52(47.7 \%)$ were at 2 hours of life, $31(28.4 \%)$ at 6 hours whereas no hypoglycemia episode recorded beyond 24 hours of life.

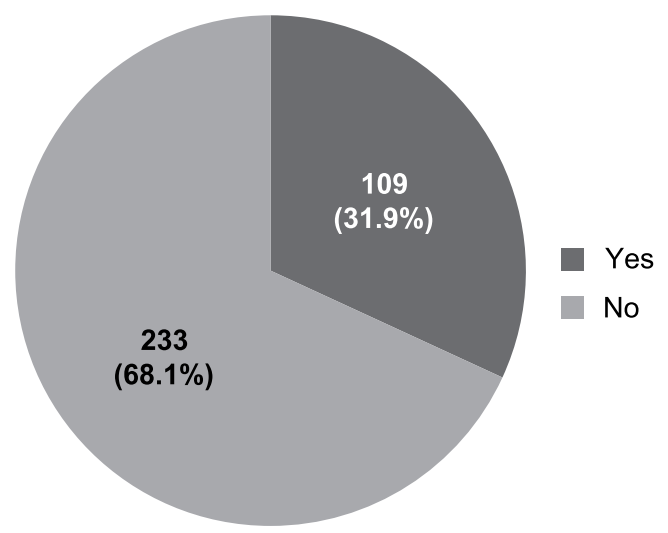

Figure-1. Hypoglycemia amongst newborns with risk factors

\section{DISCUSSION}

As this study was aimed to find out the incidence of hypoglycemia in newborns with risk factors, we found $31.9 \%$ newborns to have at least 1 hypoglycemia episode during the study period. Kumar TJ and coworkers in a recent study from Tehran found that 33.3\% newborns with risk factors had hypoglycemia. ${ }^{6}$ Kaiser et al reported $19.3 \%$ incidence of hypoglycemia in 1395 newborns with 23-42 weeks of gestational age using a blood glucose cutoff of $<45 \mathrm{mg} / \mathrm{dl}^{7}$ These numbers were much lower in comparison to the present study, possibly due to universal screening. 


\begin{tabular}{|c|c|c|c|}
\hline \multirow[b]{2}{*}{ Characteristics } & \multicolumn{2}{|c|}{ Hypoglycemia } & \multirow[b]{2}{*}{ P-Value } \\
\hline & $\begin{array}{c}\text { Yes } \\
(n=109)\end{array}$ & $\begin{array}{c}\text { No } \\
(n=233)\end{array}$ & \\
\hline \multicolumn{4}{|l|}{ Gender } \\
\hline Male & $\begin{array}{c}56 \\
(51.4 \%)\end{array}$ & $\begin{array}{c}138 \\
(59.2 \%)\end{array}$ & \multirow{2}{*}{0.172} \\
\hline Female & $\begin{array}{c}53 \\
(48.6 \%)\end{array}$ & $\begin{array}{c}95 \\
(40.8 \%)\end{array}$ & \\
\hline \multicolumn{4}{|l|}{ Gestational Age } \\
\hline $\begin{array}{l}\text { Preterm } \\
\text { (<37 weeks) }\end{array}$ & $\begin{array}{c}39 \\
(35.8 \%)\end{array}$ & $\begin{array}{c}94 \\
(40.3 \%)\end{array}$ & \multirow{2}{*}{0.420} \\
\hline Term ( $\geq 37$ weeks) & $\begin{array}{c}70 \\
(64.2 \%)\end{array}$ & $\begin{array}{c}139 \\
(59.7 \%)\end{array}$ & \\
\hline \multicolumn{4}{|l|}{ Birth Weight } \\
\hline$<2500 \mathrm{gm}$ & $\begin{array}{c}43 \\
(39.4 \%)\end{array}$ & $\begin{array}{c}109 \\
(46.8 \%)\end{array}$ & \multirow{2}{*}{0.204} \\
\hline$>2500 \mathrm{gm}$ & $\begin{array}{c}66 \\
(60.6 \%)\end{array}$ & $\begin{array}{c}124 \\
(53.2 \%)\end{array}$ & \\
\hline \multicolumn{4}{|l|}{ Status at Birth } \\
\hline $\begin{array}{l}\text { Small for } \\
\text { Gestational Age }\end{array}$ & $\begin{array}{c}62 \\
(56.9 \%)\end{array}$ & $\begin{array}{c}96 \\
(41.2 \%)\end{array}$ & \multirow{3}{*}{0.025} \\
\hline $\begin{array}{l}\text { Large for } \\
\text { Gestational Age }\end{array}$ & $\begin{array}{c}18 \\
(16.5 \%)\end{array}$ & $\begin{array}{c}50 \\
(21.5 \%)\end{array}$ & \\
\hline $\begin{array}{l}\text { Appropriate for } \\
\text { Gestational Age }\end{array}$ & $\begin{array}{c}29 \\
(26.6 \%)\end{array}$ & $\begin{array}{c}87 \\
(37.3 \%)\end{array}$ & \\
\hline \multicolumn{4}{|c|}{ Maternal Age (Years) } \\
\hline$<30$ & $\begin{array}{c}59 \\
(54.1 \%)\end{array}$ & $\begin{array}{c}147 \\
(63.1 \%)\end{array}$ & \multirow{2}{*}{0.115} \\
\hline$>30$ & $\begin{array}{c}50 \\
(45.9 \%)\end{array}$ & $\begin{array}{c}86 \\
(36.9 \%)\end{array}$ & \\
\hline \multicolumn{4}{|l|}{ Maternal BMI } \\
\hline$<25$ & $\begin{array}{c}20 \\
(18.3 \%)\end{array}$ & $\begin{array}{c}60 \\
(25.8 \%)\end{array}$ & \multirow{3}{*}{0.114} \\
\hline $25-30$ & $\begin{array}{c}34 \\
(31.2 \%)\end{array}$ & $\begin{array}{c}82 \\
(35.2 \%)\end{array}$ & \\
\hline$>30$ & $\begin{array}{c}55 \\
(50.5 \%)\end{array}$ & $\begin{array}{c}91 \\
(39.1 \%)\end{array}$ & \\
\hline \multicolumn{4}{|c|}{ Maternal History of Diabetes } \\
\hline Yes & $\begin{array}{c}32 \\
(29.4 \%)\end{array}$ & $\begin{array}{c}90 \\
(38.6 \%)\end{array}$ & \multirow{2}{*}{0.095} \\
\hline No & $\begin{array}{c}77 \\
(70.6 \%)\end{array}$ & $\begin{array}{c}143 \\
(68.4 \%)\end{array}$ & \\
\hline \multicolumn{4}{|c|}{ Maternal History of Hypertension } \\
\hline Yes & $\begin{array}{c}48 \\
(44.0 \%)\end{array}$ & $\begin{array}{c}99 \\
(42.5 \%)\end{array}$ & \multirow{2}{*}{0.788} \\
\hline No & $\begin{array}{c}61 \\
(56.0 \%)\end{array}$ & $\begin{array}{c}134 \\
(57.5 \%)\end{array}$ & \\
\hline \multicolumn{4}{|l|}{ Mode of Delivery } \\
\hline LSCS & $\begin{array}{c}70 \\
(64.2 \%)\end{array}$ & $\begin{array}{c}131 \\
(56.2 \%)\end{array}$ & \multirow{2}{*}{0.162} \\
\hline Vaginal Delivery & $\begin{array}{c}39 \\
(35.8 \%)\end{array}$ & $\begin{array}{c}102 \\
(43.8 \%)\end{array}$ & \\
\hline \multicolumn{4}{|l|}{ Parity } \\
\hline Primi Mother & $\begin{array}{c}33 \\
(30.3 \%)\end{array}$ & $\begin{array}{c}86 \\
(36.9 \%)\end{array}$ & \multirow{2}{*}{0.230} \\
\hline Multi Gravida & $\begin{array}{c}76 \\
(69.7 \%)\end{array}$ & $\begin{array}{c}147 \\
(63.1 \%)\end{array}$ & \\
\hline
\end{tabular}

Smolkin et al also reported a lower number (5\%) as compared to present study, to have hypoglycemia amongst term newborns without any risk factors. The cutoff value was labeled as $35 \mathrm{mg} / \mathrm{dl}$ in that study. ${ }^{8}$ DePuy et $\mathrm{al}^{9} 2.4 \%$ while Singh et $\mathrm{al}^{10}$ from India showed $27 \%$ incidence of hypoglycemia amongst newborns.

In the current study, incidence of hypoglycemia was more in male newborns. This pattern was also depicted by studies from $\operatorname{Iran}^{6}$ as well as India..$^{10}$ The incidence of hypoglycemia was $56.9 \%$ in present work while Kumar $\mathrm{TJ}$ et $\mathrm{al}^{6}$ got $42 \%$ incidence of hypoglycemia in SGA. Our findings had significantly more ( $p$ value $<0.05$ ) newborns as SGA in comparison to what Holtrop et al ${ }^{11}$ $(14.7 \%)$ and in Bhat et $\mathrm{al}^{12}(25.2 \%)$ reported in their studies. In Holtrop et al the frequency of hypoglycemia in SGA infants was $14.7 \%$. De AK and colleagues noted this as $64.2 \%$, but sample size was very small in that study. Holtrop, et al had excluded newborns of diabetic mothers and their newborns were not exclusively breastfed. High incidence of hypoglycemia in SGA in our study can be explained due to high risk pregnancies managed in our institution.

The incidence of hypoglycemia in low birth weight newborns was $39.4 \%$. Singh et al ${ }^{10}$ study showed incidence of hypoglycemia in low birth weight newborns 29.5\%, De AK et $\mathrm{al}^{13}$ showed $64.8 \%$ incidence of hypoglycemia in low birth weight newborns but the population size was small. ${ }^{13}$

We noted $29.4 \%$ newborns to have born with maternal history of Diabetes. Very similar results were noted in another study ${ }^{6}$ where this figure was $33 \%$ in Infants of diabetic mothers. Incidence of hypoglycemia in diabetes was found to be $28.6 \%$ in singh et $\mathrm{al}^{10}$ reports and $30 \%$ in cordero et al study. ${ }^{14}$

The frequency of hypoglycemia in LGA infants was $5 \%$ in Holtrop et al study ${ }^{11}$ and $14.6 \%$ in an Indian study. ${ }^{10}$ The incidence of hypoglycemia in LGA in this study was $16.5 \%$.

The incidence of hypoglycemia in preterm babies was $35.8 \%$, which is pretty similar to Singh et $\mathrm{al}^{10}$ 
(36.9\%) but much lower what De AK et $\mathrm{al}^{13} \mathrm{got}$ $(77.7 \%)$. Most of our preterm babies are high risk with morbidities like very low birth weight $(<1500$ grams), RDS etc., requiring NICU admission and hence not included in the present study.

In the present study, the incidence of hypoglycemia in babies born to mothers with hypertension was $44 \%$ whereas the incidence in babies born to hypertensive mothers reported by Singh et al. ${ }^{10}$ was $33.3 \%$ and $39.0 \%$ by Kumar TJ et al. ${ }^{6}$

In the present study, newborns who developed at least 1 hypoglycemia episode, 52 (47.7\%) were at 2 hours of life, $31(28.4 \%)$ at 6 hours whereas no hypoglycemia episode recorded beyond 24 hours of life. These result are very consistent what Kumar $\mathrm{TJ}$ et $\mathrm{al}^{6}$ from Iran observed in his findings. No babies developed hypoglycemia after 24 hours of life. So, newborns with risk factors for hypoglycemia should be screened at regular interval for blood glucose level more specifically at first 24 hours of life to enable us to support breastfeeding to prevent hypoglycemia and potential neurodevelopmental damage.

As far as limitations of present study are concerned, all infants could not feed within the first hour. This study showed that health professionals should be informed about the follow-up of infants bearing the risk of hypoglycemia.

\section{CONCLUSION}

Screening for hypoglycemia should always be performed in babies who had risk factors of hypoglycemia especially within 24 hours of life. As per our study blood glucose screening should be mandatory in all newborns who are SGA.

Copyright@ 10 June, 2019.

\section{REFERENCES}

1. Boluyt N, van Kempen A, Offringa M. Neurodevelopment after neonatal hypoglycemia: A systematic review and design of an optimal future study. Pediatrics 2006; 117:2231e43.

2. Committee on Fetus and Newborn, Adamkin DH. Postnatal glucose homeostasis in late-preterm and term infants. Pediatrics 2011; 127:575e9.
3. Cornblath M, Ichord R. Hypoglycemia in the neonate. Semin Perinatol 2000; 24:136e49.

4. Harris DL, Weston P, Harding JE. Incidence of neonatal hypoglycemia in babies identified as at risk. J Pediatr. 2012; 161:787e91.

5. Pal DK, Manandhar DS, Rajbhandari S, RB, Land JM, Patel N, et al. Neonatal hypoglycaemia in Nepal 1. Prevalence and risk factors. Archives of Disease in Childhood 2000; 82: F46-51.

6. Kumar TJ, Vaideeswaran M, Arasar ST. Incidence of hypoglycemia in newborns with risk factors. Kumar TJ et al. Int J Contemp Pediatr. 2018 Sep; 5(5):19521955.

7. Kaiser JR, Bai S, Gibson N. Association between transient neonatal hypoglycemia and fourth-grade achievement test proficiency. A population-based study. JAMA Pediatr. 2015; 169(10):913-21.

8. Smolkin T, Ulanovsky I, Carasso P. Standards of admission capillary blood glucose levels in cesarean born neonates. World J Pediatr. 2017; 13(5):433-8.

9. DePuy AM, Coassolo KM, Som DA. Neonatal hypoglycemia in term, nondiabetic pregnancies. Am J Obstet Gynecol. 2009; 200(5):e45-e51.

10. Singh P, Upadhyay A, Sreenivas V, Jaiswal V, Saxena P. Screening for hypoglycemia in exclusively breastfed high-risk neonates. Indian pediatrics. 2017; 54(6):47780.

11. Holtrop PC. The frequency of hypoglycemia in full term large and small for gestational age newborns. Am J Perinatol. 1993; 10:150-64.

12. Bhat MA, Kumar P, Bhansali A, Majumdar S, Narang A. Hypoglycemia in small for gestational age babies. Indian J Pediatr. 2000; 67:4.

13. De AK, Biswas R, Samanta M, Kundu CK. Study of blood glucose level in normal and low birth weight newborns and impact of early breast-feeding in a tertiary care Centre. Ann Nigerian Med. 2011; 5:53-8.

14. Cordero L, Thung S, Landon MB, Nankervis CA. Breastfeeding initiation in women with pregestational diabetes mellitus. Clinical Pediatr. 2014; 53(1):18-25. 


\section{AUTHORSHIP AND CONTRIBUTION DECLARATION}

\begin{tabular}{|c|c|c|c|}
\hline Sr. \# & Author(s) Full Name & Contribution to the paper & Author(s) Signature \\
\hline 3 & $\begin{array}{l}\text { Muhammad Ejaz Mazari } \\
\text { Fazal ur Rehman } \\
\text { Muhammad Ashfaq Zafar }\end{array}$ & $\begin{array}{l}\text { Methodology, Literature } \\
\text { Review, Data analysis. } \\
\text { Methodology, Literature } \\
\text { Review, Data analysis, } \\
\text { Drafting. } \\
\text { Data collection, Data } \\
\text { handling, Literature Review. }\end{array}$ & (lid \\
\hline
\end{tabular}

